\title{
Форстеритовый концентрат Ковдорского ГОКа - сырье для получения бетона на магнезиальном вяжущем
}

\section{Белогурова О.А., Саварина М.А., Шарай Т.В.}

Институт химии и технологии редких элементов и минерального сырья им. И.В. Тананаева КНЦ РАН, Anamumbl,belog_oa@chemy.kolasc.net.ru

Аннотация. Основное направление в стратегии долгосрочного недропользования - получение материалов из минерально-сырьевых ресурсов техногенных скоплений. На основе отходов Ковдорского горнообогатительного комбината и магнезиального цемента разработаны составы и определены свойства огнеупорных бетонов. Вяжущим компонентом для бетонов из форстеритового концентрата как сырого, так и брикетированного, послужил каустический магнезит и химическая связка из гидратной соли $\mathrm{MgCl}_{2} \cdot 6 \mathrm{H}_{2} \mathrm{O}$. $\mathrm{B}_{\text {ыяв- }}$ лены экспериментальные зависимости прочности форстеритового бетона от количества каустического магнезита и тонкой фракции наполнителя в шихте, плотности водного раствора гидратной соли.

Ключевые слова: форстеритовый концентрат, брикет, каустический магнезит, бишофит, бетон

\section{Kovdorsky GOK's forsterite concentrate - raw materials for concrete using a magnesian binder}

\author{
Belogurova O.A., Savarina M.A., Sharai T.V. \\ Tananaev Institute of Chemistry and Technology of Rare Elements and Mineral Raw Materials of the Kola \\ Science Centre, RAS, Apatity, belog_oa@chemy.kolasc.net.ru
}

\begin{abstract}
The main direction in the strategy of long-term subsoil use is to obtain materials from the mineral resources of technogenic accumulations. Compositions have been developed and the properties of refractory concrete have been determined based on wastes from the Kovdorsky mining and processing plant and the magnesia cement. Caustic magnesite and a chemical binder based on crystal hydrate $\mathrm{MgCl}_{2} \cdot 6 \mathrm{H}_{2} \mathrm{O}$ served as a binding component for concrete from forsterite concentrate, both raw and briquetted. Experimental dependences of the strength of forsterite concrete on the amount of caustic magnesite and a fine fraction of the forsterite concentrate or briquette in the mixture, and the density of water solution of the hydrated salt have been revealed.
\end{abstract}

Key words: forsterite concentrate, briquette, caustic magnesite, bischofite, concrete.

Отходы горного производства - уникальный источник многих ценных полезных ископаемых. Комплексная оценка попутных компонентов, содержащихся в основных полезных ископаемых, проводится недостаточно. К числу факторов, увеличивающих затраты на разработку техногенных месторождений и определяющих отсутствие заинтересованности потенциальных инвесторов в их разработке, относятся: более низкое качество техногенного сырья по сравнению с природными месторождениями; сложность и высокая стоимость извлечения твердых компонентов, обусловленные физико-химическими свойствами сырья; невостребованность определенных видов сырья при наличии существенных объемов; экологические риски. В результате отходы добычи минерального сырья используются не эффективно (Вержанский А.П., 2016).

Следует отметить ряд положительных факторов для Ковдорского ГОКа, способствующих снижению затрат на освоение техногенных отвалов: расположение их в районе с развитой промышленной и транспортной инфраструктурой; размещение отходов горного производства не в недрах, а преимущественно на земной поверхности; раздробленное состояние горной массы; наличие перерабатывающих мощностей. Развитие новых технологий переработки подобного вида минерального сырья может привести к получению востребованных продуктов.

Технология обогащения комплексных железных руд Ковдорского месторождения предусматривает последовательное выделение железорудного (магнетитового), апатитового и бадделеитового концентратов. Отходы обогатительного производства представлены, мас. \%: форстеритом 38-48, кальцитом 21-30, флогопитом 10-11 и не извлеченной частью основных продуктов. 
Перспективы развития предприятия связаны с увеличением полноты и комплексности извлечения полезных компонентов и получением новых нетрадиционных видов продукции, одним из которых является форстерит - сырье для производства огнеупорных материалов.

Цель работы - разработка технологии бетона из форстеритового концентрата Ковдорского ГОКа на магнезиальном цементе.

Магнезиальное вяжущее состоит из оксида магния, который получают при прокаливании мелкодисперсного магнезита или гидроксида магния при температуре $800^{\circ} \mathrm{C}$, и химической связки из водного раствора гидратной соли $\mathrm{MgCl}_{2} \cdot 6 \mathrm{H}_{2} \mathrm{O}$. Вследствие образования полимерной структуры из ионов магния, связанных друг с другом посредством гидроксильных групп, молекул воды и ионов хлора, смесь отвердевает, образуя плотный, прочный камень. Как правило, магнезиальный цемент маркируется цифрами 500 и выше. Среди основных достоинств магнезиальных цементов можно отметить высокую скорость затвердевания, прочность и адгезию к различным наполнителям. Кроме того, эти сорта цемента отличаются повышенной эластичностью, огнестойкостью и невысокой теплопроводностью. При получении изделий на основе магнезиального вяжущего необходимо соблюдение достаточно жесткого соотношения каустического магнезита и гидратной соли. Важным фактором повышения конструкционных свойств материала является определение соотношения наполнителя и магнезиального цемента.

Химический анализ форстеритового концентрата из отходов обогатительного производства, мас. \%: $\mathrm{MgO}$ - 43-48; $\mathrm{SiO}_{2}$ - 33-39; $\mathrm{FeO}$ - 4.4-5.3; $\mathrm{Fe}_{2} \mathrm{O}_{3}-0.8-5.9 ; \mathrm{CaO}$ - 0.6-2.4; п.п.П. - 0.1-1.5. Гранулометрический состав сырого форстеритового концентрата, мас. \%: (+0.2 мм) - 8, (-0.2+0.16 мм) - 27, $(-0.16+0.063$ мм $)-41,(-0.063$ мм $)-24$.

Для уменьшения влияния примесей и повышения огнеупорных свойств материала к форстеритовому концентрату, полученному из отходов обогатительного производства Ковдорского ГОКа, необходимо добавлять оксид магния, в данной работе использован бой магнезитовых изделий. Состав шихты для брикета, мас. \%: 50 - форстеритовый концентрат $<0.2$ мм и 15 форстеритовый концентрат $<0.063$ мм, 35 - бой магнезитовых изделий $<0.2$ мм.

Технологическая схема получения брикета: компоненты шихты перемешивают, вводят связку (поливиниловый спирт), прессуют под давлением 50-70 МПа, высушивают в естественных условиях в течение суток, затем обжигают при температуре $1400^{\circ} \mathrm{C}$. Брикет дробят, часть подвергают помолу в виброистирателе ИВ 1 для получения фракции $<0.063$ мм. Гранулометрический состав раздробленного брикета, мас. \%: $(-3+2.5$ мм $)-1,(-2.5+1.6$ мм $)-14,(-1.6+1$ мм $)-9$, $(-1+0.63$ мм $)-7,(-0.63+0.4$ мм $)-6,(-0.4+0.315$ мм $)-10,(-0.315+0.2$ мм $)-15,(-0.2+0.16$ мм $)-8$, $(-0.16+0.063$ мм $)-14,(<0.063$ мм $)-16$.

Вяжущим компонентом для бетонов из форстеритового концентрата как сырого, так и брикетированного, послужил каустический магнезит и химическая связка из водного раствора гидратной соли $\mathrm{MgCl}_{2} \cdot 6 \mathrm{H}_{2} \mathrm{O}$.

Рентгенофазовый анализ, полученных бетонов, проводили на дифрактометре ДРФ -2 ( $\mathrm{CuK}$-излучение). Фрактографические исследования выполнены на растровом электронном микроскопе с использованием SEM LEO 420.

Прочность бетонов определяли с учетом требований ГОСТ 10180-2012 «Бетоны. Методы определения прочности по контрольным образцам», плотность согласно ГОСТ 52541-2006 «Бетоны огнеупорные».

Физико-химическим исследованиям процесса твердения магнезиального цемента посвящен целый ряд работ отечественных и зарубежных ученых, но единой и общепринятой теории до сих пор нет.

В системе $\mathrm{MgO}-\mathrm{MgCl}_{2}-\mathrm{H}_{2} \mathrm{O}$ выявлены различные соединения и условия их получения. Считается, что при соотношении $4<\mathrm{MgO} / \mathrm{MgCl}_{2}<6$ в системе $\mathrm{MgO}-\mathrm{MgCl}_{2}-\mathrm{H}_{2} \mathrm{O}$ после затвердевания преобладает устойчивая фаза пентаоксихлорида магния $5 \mathrm{Mg}(\mathrm{OH})_{2} \cdot \mathrm{MgCl}_{2} \cdot 8 \mathrm{H}_{2} \mathrm{O}$, который со временем может переходить в триоксигидрохлорид магния $3 \mathrm{Mg}(\mathrm{OH})_{2} \cdot \mathrm{MgCl}_{2} \cdot 8 \mathrm{H}_{2} \mathrm{O}$. Скорость перекристаллизации пентаоксигидрохлорида может увеличиваться при снижении отношения $\mathrm{MgO}: \mathrm{MgCl}_{2}$. Смесь 
гидроксида магния и пентаоксигидрохлорида образуется при соотношении $\mathrm{MgO}: \mathrm{MgCl}_{2}$ больше 6 (Dehya D. et al., 1999).

B paботе (Matkovic B. et al., 1973) отмечено, что при использовании химической связки из водного раствора гидратной соли $\mathrm{MgCl}_{2} \cdot 6 \mathrm{H}_{2} \mathrm{O}$ в начале гидратации кристаллизуется $5 \mathrm{MgO} \cdot \mathrm{MgCl}_{2} \cdot 13 \mathrm{H}_{2} \mathrm{O}$. Высокая прочность этого соединения обусловлена наличием прорастания друг в друга нитевидных агрегатов. Они предположили, что иглы сформировались в областях пористости. Эти авторы заявили, что после заполнения пустот кристаллитами микроструктура магнийоксихлоридного цемента начинает уплотняться. Часть исследователей отмечает, что в магнезиальном цементе в составе преобладает $5 \mathrm{MgO} \cdot \mathrm{MgCl}_{2} \cdot 13 \mathrm{H}_{2} \mathrm{O}$ с небольшим количеством фазы $3 \mathrm{MgO} \cdot \mathrm{MgCl}_{2} \cdot 11 \mathrm{H}_{2} \mathrm{O}$.

Согласно многим работам стабильными фазами оксихлоридов в системе $\mathrm{MgO}-\mathrm{MgCl}_{2}-\mathrm{H}_{2} \mathrm{O}$ являются (Runchevski T. et al., 2014; Walling S.A. et al., 2016; Jurišová J. et al., 2015):

$$
\begin{aligned}
& \left.-2 \mathrm{Mg}(\mathrm{OH})_{2} \cdot \mathrm{MgCl}_{2} \cdot 4 \mathrm{H}_{2} \mathrm{O}=\mathrm{Mg}_{3}(\mathrm{OH})_{4} \mathrm{Cl}_{2}\left(\mathrm{H}_{2} \mathrm{O}\right)_{4} \text { (фаза «2» или «2: } 1: 4 »\right) \\
& -3 \mathrm{Mg}(\mathrm{OH})_{2} \cdot \mathrm{MgCl}_{2} \cdot 8 \mathrm{H}_{2} \mathrm{O}=\mathrm{Mg}_{2}(\mathrm{OH})_{3} \mathrm{Cl}_{2}\left(\mathrm{H}_{2} \mathrm{O}\right)_{4}(\text { фаза «3» или «3: } 1: 8 ») \\
& -5 \mathrm{Mg}(\mathrm{OH})_{2} \cdot \mathrm{MgCl}_{2} \cdot 8 \mathrm{H}_{2} \mathrm{O}=\mathrm{Mg}_{3}(\mathrm{OH})_{5} \mathrm{Cl}_{2}\left(\mathrm{H}_{2} \mathrm{O}\right)_{4}(\text { фаза «5», «5: } 1: 8 ») \\
& -9 \mathrm{Mg}(\mathrm{OH})_{2} \cdot \mathrm{MgCl}_{2} \cdot 5 \mathrm{H}_{2} \mathrm{O}=\mathrm{Mg}_{10}(\mathrm{OH})_{18} \mathrm{Cl}_{2}\left(\mathrm{H}_{2} \mathrm{O}\right)_{5}(\text { фаза «9», «9: 1: } 5 »)
\end{aligned}
$$

В данном исследовании отмечено, что на рентгенограммах бетона присутствуют линии магнезиальных оксихлоридных соединений: $\mathrm{Mg}_{3}(\mathrm{OH})_{5} \mathrm{Cl}\left(\mathrm{H}_{2} \mathrm{O}\right)_{4}$ (на основе сырого форстеритового концентрата), $\mathrm{Mg}_{3}(\mathrm{OH})_{5} \mathrm{Cl}\left(\mathrm{H}_{2} \mathrm{O}\right)_{4}$ и $\mathrm{Mg}_{2}(\mathrm{OH})_{3} \mathrm{Cl}\left(\mathrm{H}_{2} \mathrm{O}\right)_{4}$ (на основе брикета), $\mathrm{Mg}_{3}(\mathrm{OH})_{5} \mathrm{Cl}\left(\mathrm{H}_{2} \mathrm{O}\right)_{4}$ и $\mathrm{Mg}_{3}$ $(\mathrm{OH})_{4} \mathrm{Cl}_{2}\left(\mathrm{H}_{2} \mathrm{O}\right)_{4}$ (при использовании совместного помола брикета и каустического магнезита), а также оксида магния. На рисунке 1 представлена поверхностная структура игольчатых агрегатов оксихлоридов магния, обуславливающих высокую прочность.

Состав фаз бетона с использованием магнезиального цемента зависит от соотношения исходных компонентов наполнителя, концентрации раствора $\mathrm{MgCl}_{2} \cdot 6 \mathrm{H}_{2} \mathrm{O}$.

Основные технологические этапы получения бетонов: в шихту определенного фракционного состава на основе форстерита (сырого или обожженного) вводили каустический магнезит, переме-

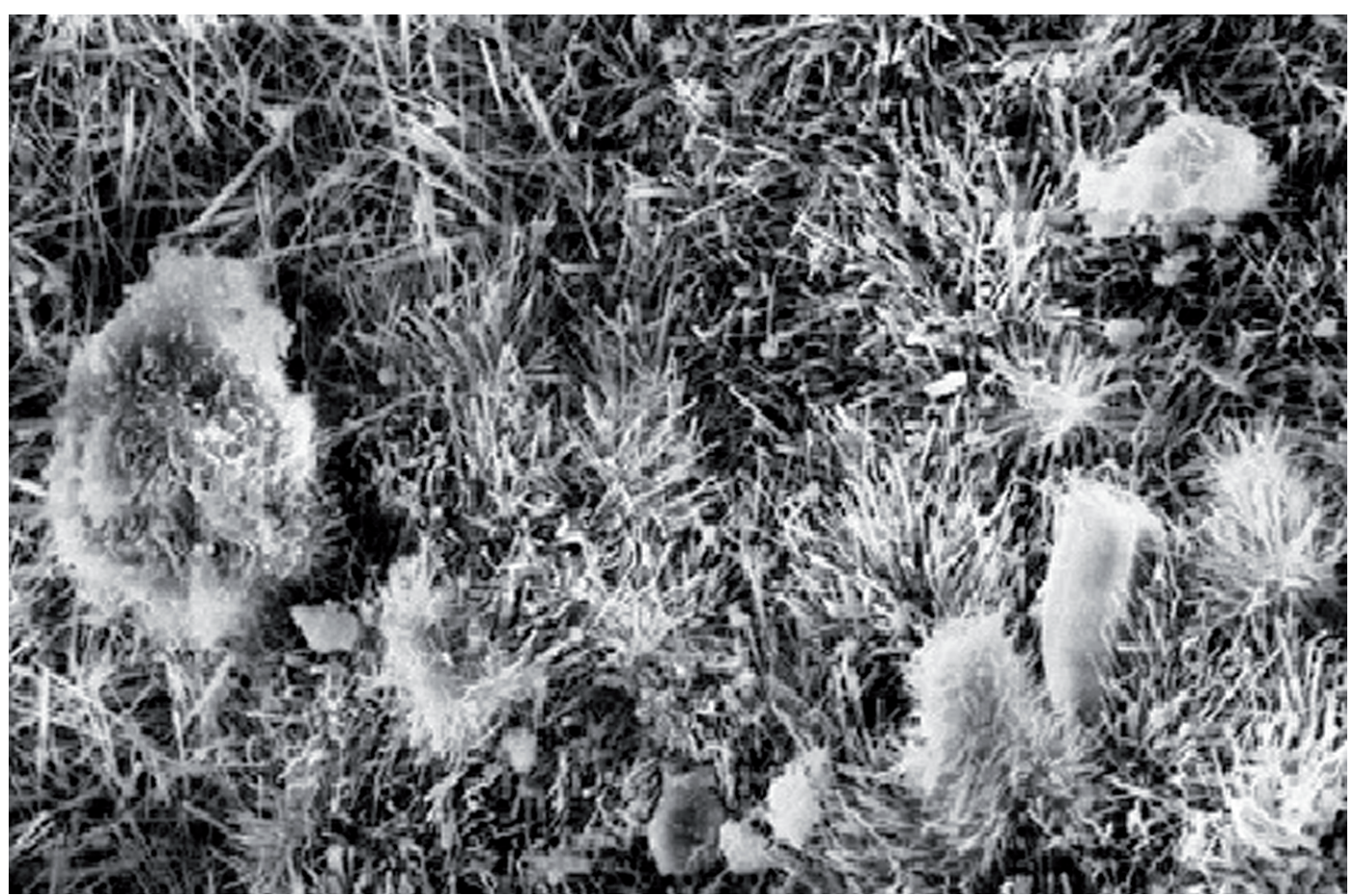

Рис. 1. SEM-микрофотография поверхностной структуры игольчатых агрегатов оксихлоридов магния (аналитик, к.х.н. Семушин В.В.).

Fig. 1. SEM micrograph of the surface structure of needle aggregates of magnesium oxychlorides (analyst, Ph.D. (Chem.) Semushin V.V.) 
шивали, добавляли определенное водного раствора гидратной соли $\mathrm{MgCl}_{2} \cdot 6 \mathrm{H}_{2} \mathrm{O}$, перемешивали и укладывали в форму $40 \times 40 \times 40$ мм. После твердения на воздухе в течение 5 суток, определяли плотность и прочность при сжатии. В таблицах 1, 2 приведены данные по прочности бетонов из сырого форстеритового концентрата.

Таблица 1. Свойства бетонов при содержании каустического магнезита -25 мас. \%

Table 1. Properties of concrete, where the quantity of caustic magnesite is $25 \mathrm{wt} . \%$.

\begin{tabular}{|c|c|c|c|c|c|}
\hline № & $\begin{array}{c}\text { Плотность водного раствора } \\
\mathrm{MgCl}_{2} \cdot 6 \mathrm{H}_{2} \mathrm{O}, \Gamma / \mathrm{cm}^{3}\end{array}$ & 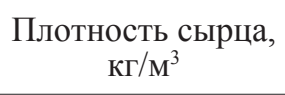 & $\begin{array}{c}\text { Фракция } \\
<0.2 \text { мм, мас. \% }\end{array}$ & $\begin{array}{c}\text { Фракция } \\
<0.063 \text { мм, мас. \% }\end{array}$ & $\begin{array}{l}\text { Прочность, } \\
\text { МПа }\end{array}$ \\
\hline 1 & 1.155 & 2090 & 75 & - & 25 \\
\hline 2 & 1.259 & 2160 & 75 & - & 28 \\
\hline 3 & 1.155 & 2140 & 50 & 25 & 26 \\
\hline 4 & 1.259 & 2120 & 50 & 25 & 25 \\
\hline
\end{tabular}

Таблица 2. Свойства бетонов при содержании каустического магнезита - 35 мас. \%.

Table 2. Properties of concrete, where the quantity of caustic magnesite is $35 \mathrm{wt} . \%$.

\begin{tabular}{|c|c|c|c|c|c|}
\hline № & $\begin{array}{c}\text { Плотность водного раствора } \\
\mathrm{MgCl}_{2} \cdot 6 \mathrm{H}_{2} \mathrm{O}, \mathrm{r}_{\mathrm{cm}} \mathrm{cm}^{3}\end{array}$ & $\begin{array}{c}\text { Плотность сырца, } \\
\kappa \Gamma / \mathbf{M}^{3}\end{array}$ & $\begin{array}{c}\text { Фракция } \\
<0.2 \text { мм, мас. \% }\end{array}$ & $\begin{array}{c}\text { Фракция } \\
<0.063 \text { мм, мас.\% }\end{array}$ & $\begin{array}{l}\text { Прочность, } \\
\text { МПа }\end{array}$ \\
\hline 1 & 1.155 & 2030 & 65 & - & 27 \\
\hline 2 & 1.259 & 2150 & 65 & - & 36 \\
\hline 3 & 1.155 & 2140 & 40 & 25 & 27 \\
\hline 4 & 1.259 & 2120 & 40 & 25 & 45 \\
\hline
\end{tabular}

На основании анализа данных сделано заключение, что прочность бетона из сырого форстеритового концентрата возрастает с увеличением концентрации каустического магнезита в составе шихты и плотности водного раствора $\mathrm{MgCl}_{2} \cdot 6 \mathrm{H}_{2} \mathrm{O}$. Количество тонкой фракции форстеритового концентрата повышает прочность только в случае использования в шихте 35 мас. \% каустического магнезита при плотности водного раствора $\mathrm{MgCl}_{2} \cdot 6 \mathrm{H}_{2} \mathrm{O}=1.259$ г $/ \mathrm{cm}^{3}$.

В таблицах 3, 4 приведены данные по прочности бетонов на основе брикета из форстеритового концентрата и боя магнезитовых изделий (состав приведен выше).

Таблица 3. Свойства бетонов при содержании каустического магнезита - 25 мас. \%.

Table 3. Properties of concrete, where the quantity of caustic magnesite is $25 \mathrm{wt}$. \%.

\begin{tabular}{|c|c|c|c|c|c|}
\hline № & $\begin{array}{c}\text { Плотность водного раствора } \\
\mathrm{MgCl}_{2} \cdot 6 \mathrm{H}_{2} \mathrm{O}, \Gamma / \mathrm{cm}^{3}\end{array}$ & $\begin{array}{c}\text { Плотность сырца, } \\
\kappa \Gamma / \mathrm{M}^{3}\end{array}$ & $\begin{array}{c}\text { Фракция } \\
<3 \text { мм, мас. \% }\end{array}$ & $\begin{array}{c}\text { Фракция } \\
<0.063 \text { мм, мас. }\end{array}$ & $\begin{array}{l}\text { Прочность, } \\
\text { МПа }\end{array}$ \\
\hline 1 & 1.155 & 2100 & 55 & 20 & 34 \\
\hline 2 & 1.259 & 2210 & 55 & 20 & 40 \\
\hline 3 & 1.155 & 2100 & 45 & 30 & 33 \\
\hline 4 & 1.259 & 2170 & 45 & 30 & 38 \\
\hline 5 & 1.155 & 2120 & 40 & 35 & 31 \\
\hline 6 & 1.259 & 2200 & 40 & 35 & 39 \\
\hline 7 & 1.155 & 2120 & 35 & 40 & 30 \\
\hline 8 & 1.259 & 2150 & 35 & 40 & 35 \\
\hline
\end{tabular}

На рисунках 2, 3 представлены графические зависимости прочности бетонов от содержания тонкой фракции форстеритового брикета в шихте, количества каустического магнезита и плотности водного раствора $\mathrm{MgCl}_{2} \cdot 6 \mathrm{H}_{2} \mathrm{O}$.

Отмечено, что увеличение содержания тонкой фракции брикета не привело к повышению показателя прочности. Бетон из шихты, содержащей 20 мас. \% брикета фракции менее 0.063 мм, обладал прочностью выше 50 МПа. Однако, при использовании смеси совместного помола каустиче- 
ского магнезита и брикета (фракция менее 0.063 мм) прочность возросла до 80 МПа. Изменение количества каустического магнезита и повышение плотности водного раствора $\mathrm{MgCl}_{2} \cdot 6 \mathrm{H}_{2} \mathrm{O}$ способствует увеличению прочности бетона. Для бетона из брикета отмечена более высокая прочность по сравнению с образцами на основе сырого форстеритового концентрата.

Таблица 4. Свойства бетонов при содержании каустического магнезита - 35 мас. \%.

Table 4. Properties of concrete, where the quantity of caustic magnesite is 35 wt. \%.

\begin{tabular}{|c|c|c|c|c|c|}
\hline № & $\begin{array}{c}\text { Плотность водного раствора } \\
\mathrm{MgCl}_{2} \cdot 6 \mathrm{H}_{2} \mathrm{O}, \Gamma / \mathrm{cm}^{3}\end{array}$ & $\begin{array}{c}\text { Плотность сырца, } \\
\kappa \Gamma / \mathrm{M}^{3}\end{array}$ & $\begin{array}{c}\text { Фракция } \\
<3 \text { мм, мас. \% } \\
\end{array}$ & $\begin{array}{c}\text { Фракция } \\
<0.063 \text { мм, мас. \% }\end{array}$ & $\begin{array}{l}\text { Прочность, } \\
\text { МПа }\end{array}$ \\
\hline 1 & 1.155 & 2050 & 45 & 20 & 36 \\
\hline 2 & 1.259 & 2190 & 45 & 20 & 51 \\
\hline $2 *$ & 1.259 & 2160 & 45 & $20+20$ & 57 \\
\hline $2 * *$ & 1.259 & 2290 & 45 & $20+35$ & 80 \\
\hline 3 & 1.155 & 2050 & 35 & 30 & 34 \\
\hline 4 & 1.259 & 2080 & 35 & 30 & 41 \\
\hline 5 & 1.155 & 2120 & 30 & 35 & 35 \\
\hline 6 & 1.259 & 2200 & 30 & 35 & 37 \\
\hline
\end{tabular}

$2 *$ совместный помол брикета $(20 \%)$ и каустического магнезита (20\%).

2 ** совместный помол брикета (20 \%) и каустического магнезита (35\%).

Таким образом, в результате исследования разработаны составы бетонов из отходов Ковдорского горно-обогатительного комбината и магнезиального цемента, определены их характеристики, выявлены экспериментальные зависимости прочности форстеритового бетона от количества каустического магнезита и тонкой фракции наполнителя в шихте, плотности гидратной соли $\mathrm{MgCl}_{2} \cdot 6 \mathrm{H}_{2} \mathrm{O}$.

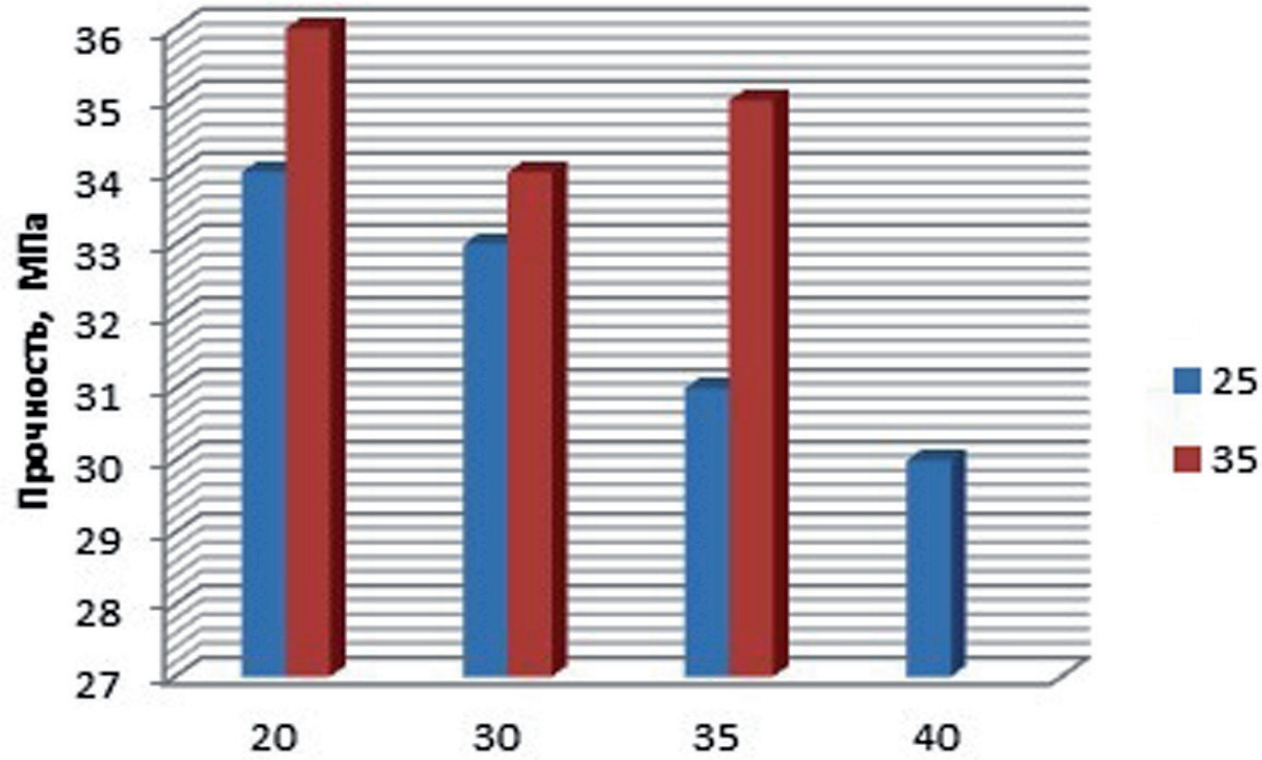

Количество фракции брикета менее 0.063 мм

Рис. 2. Зависимость прочности бетона от количества тонкой фракции брикета и каустического магнезита (легенда), плотность водного раствора $\mathrm{MgCl}_{2} \cdot 6 \mathrm{H}_{2} \mathrm{O}=1.155$ г $/ \mathrm{cm}^{3}$.

Fig. 2. Dependence of concrete strength on the amount of fine fraction of briquette and caustic magnesite (legend), the density of an aqueous solution of $\mathrm{MgCl}_{2} \cdot 6 \mathrm{H}_{2} \mathrm{O}=1.155 \mathrm{~g} / \mathrm{cm}^{3}$. 


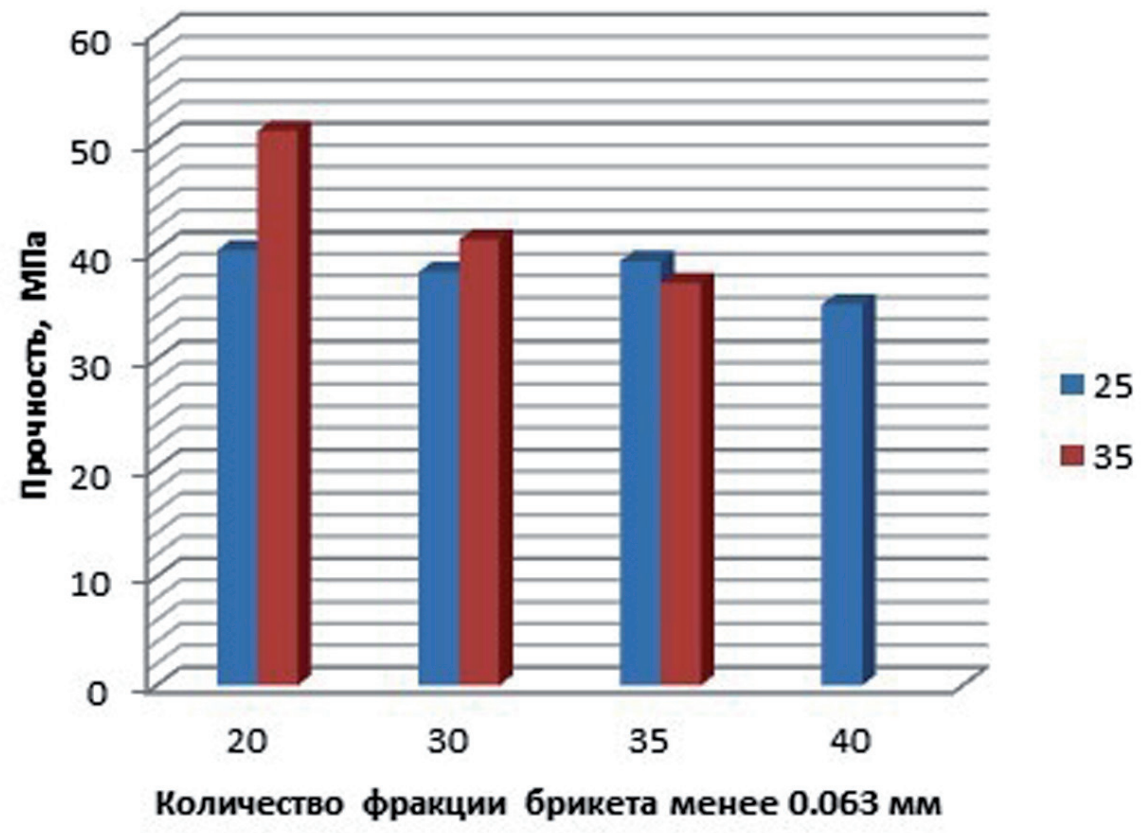

Рис. 3. Зависимость прочности бетона от количества тонкой фракции брикета и каустического магнезита (легенда), плотность водного раствора $\mathrm{MgCl}_{2} \cdot 6 \mathrm{H}_{2} \mathrm{O}=1.259$ г $/ \mathrm{cm}^{3}$.

Fig. 3. Dependence of concrete strength on the amount of fine fraction of briquette and caustic magnesite (legend), the density of an aqueous solution of $\mathrm{MgCl}_{2} \cdot 6 \mathrm{H}_{2} \mathrm{O}=1.259 \mathrm{~g} / \mathrm{cm}^{3}$.

Работа выполнена в рамках темы НИР № 0226-2019-0068.

\section{Литература}

1. Вержанский А.П. // Сетевое издание «Редкие земли» http: //rare-earth.ru.

2. Dehya D., Chuanmei Z. The formation mechanism of the hydrate phases in magnesium oxichloride cement // Cement and Concrete Research. 1999. 29. P. 1365-1371.

3. Jurišová J., Fellner P., Pach L. Characteristics of Sorel cement prepared from impure materials // Acta Chimica Slovaca. 2015. 8 (2). P. 87-90. DOI:10.515/acs-2015-0015.

4. Matkovic B., Young J.F. Microstructure of magnesium oxychloride cements // Nature. Phys. Sci. 1973. 246. P. 79-80.

5. Runchevski T., Dinnebier R.E., Freyer D. Dehydration of the Sorel cement phase $3 \mathrm{Mg}(\mathrm{OH})_{2} \cdot \mathrm{MgCl}_{2} \cdot 8 \mathrm{H}_{2} \mathrm{O}$ studied by in situ synchrotron X-ray powder diffraction and thermal analysis // Z.Anorg.Allg.Chem. 2014. 640 (1). P. 100-105. DOI: 10.1002/zaac.201300229.

6. Walling S.A., Provis J.I. Magnesia- Based Cements: A Journey of 150 Years, and Cements for the Future // Chem. Rev. 2016. 116. P. 4170-4204. DOI: 10.1021/acs.chemrev.Sb00463. 